\title{
Laparoscopic management of appendicitis and symptomatic cholelithiasis during pregnancy
}

\author{
Nermin Halkic • Adrien A. Tempia-Caliera • \\ Riadh Ksontini • Michel Suter • \\ Jean-François Delaloye $\cdot$ Henri Vuilleumier
}

Received: 14 December 2005 / Accepted: 27 April 2006/ Published online: 15 August 2006

(C) Springer-Verlag 2006

\begin{abstract}
Background Laparoscopic surgery during pregnancy is a challenging procedure that most surgeons are reluctant to perform. The objective of this study was to evaluate whether laparoscopic appendectomy and cholecystectomy is safe in pregnant women. The management of these situations remains controversial. We report a single center study describing the successful management of 16 patients during pregnancy.

Methods More than 3,356 laparoscopic procedures were performed in our institutions between May 1990 and June 2005. Sixteen of these patients were operated on in the second and third trimester between 22 and 32 weeks of estimated gestational age. We performed 11 laparoscopic appendectomies and 5 laparoscopic cholecystectomies. We also reviewed the management and operative technique used in these patients.

Results In this study, the laparoscopic appendectomy or cholecystectomy was performed successfully in all patients. Three patients were in their second trimester, weeks 22, 23, and 25 , and 13 were in the third trimester, weeks 27 (three patients), 28 (five patients), 31 (three patients), and 32 (two patients). No maternal or fetal morbidity occurred. Open laparoscopy was performed safely in all patients and all patients delivered healthy babies.
\end{abstract}

\footnotetext{
N. Halkic $(\bowtie) \cdot$ A. A. Tempia-Caliera $\cdot$ R. Ksontini $\cdot$ M. Suter $\cdot$

H. Vuilleumier

Service de Chirurgie, CHUV, University of Lausanne,

Lausanne 1011, Switzerland

e-mail: Nermin.Halkic@chuv.hospvd.ch

J.-F. Delaloye

Service de Gynécologie et Obstétrique, CHUV,

University of Lausanne,

Lausanne 1011, Switzerland
}

Conclusion From our experience laparoscopic management of appendicitis and biliary colic during pregnancy is safe, however the second trimester is preferable for laparoscopic cholecystectomy. Pregnancy is not a contraindication to the laparoscopic approach to appendicitis or symptomatic cholelithiasis. We believe that laparoscopic operations, when performed by experienced surgeons, are safe and even preferable for the mother and the fetus.

Keywords Pregnancy · Laparoscopic appendectomy · Cholecystectomy $\cdot$ Appendicitis · Symptomatic cholelithiasis

\section{Introduction}

Acute appendicitis and symptomatic cholecystolithiasis are common nonobstetrical emergencies in pregnant women $[1,2]$ and occurs in about 1 to 500 pregnancies [3].

Acute appendicitis occurs with the same frequency in gravid and in nongravid females of the same age, leading to appendectomy in one out of every 1,500 pregnancies [1-5]. Anatomically, the appendix is displaced out of the right lower quadrant to the right lateral upper quadrant. Leukocytosis is common in uneventful pregnancy [4, 6, 7]. Diagnostic studies, including ultrasound, are of little help; only a physical examination is reliable. Laparoscopic exploration can help to the diagnosis and be therapeutic. Delay with resultant appendiceal rupture with peritonitis has fetal consequences [8]. Peritonitis after perforation increases the risk of unstable gestation and fetal losses are up to $20 \%$ in cases of perforated appendicitis and up to $35.7 \%$ in generalized peritonitis compared to less than $5 \%$ in case of uncomplicated acute appendicitis [6]. Thus, clinical suspicion of acute appendicitis during pregnancy is an indication for surgical exploration [2]. 
Biliary tract disease occurs in about 1 to 6 out of 1,000 pregnancies and requires surgical intervention less frequently, partly due to the availability of effective nonsurgical therapeutic alternatives [1,9]. Cholecystectomy is required in about $40 \%$ of pregnant women with symptomatic biliary colic [10]. Pregnancy may predispose women to gallbladder disease by increasing stone formation and possibly increasing symptoms in women with preexisting cholelithiasis $[9,11]$. Fetal losses for cholecystectomy is approximately 5\% [4]. However, acute biliary pancreatitis was associated with a $15 \%$ maternal mortality and up to $60 \%$ fetal losses [4].

Although published studies have described successful procedures, laparoscopic surgical intervention remains limited [12]. In many minds, pregnancy is still considered to be a contraindication and physicians have a tendency to postpone surgical intervention for as long as possible, best until after delivery $[13,14]$. However preterm delivery, birth defects, 5-min Apgar score, and low-birth-weight after laparoscopic appendicectomy or cholecystectomy are possible without significant increase in morbidity or mortality $[15,16]$. We present here our experience in laparoscopic management of acute appendicitis and symptomatic biliary colic in the pregnant women.

\section{Materials and methods}

During a 15-year period from 1990 to 2005 , the clinical files of patients who were operated laparoscopically were reviewed. All the charts of patients that were taken to the operating room for appendix or gallbladder disease during pregnancy were analyzed. Clinical and pathology reports were reviewed to confirm the diagnosis and to obtain maternal outcome. Pregnancy outcome information, such as birth weight, fetal losses, gestational duration, congenital malformations, stillbirths, and neonatal deaths, were obtained by directly contacting the patient or the patient's obstetrician.

The Hasson technique of open laparoscopy was performed systematically. To prevent puncturing the gravid uterus the position of the initial trocar was controlled by ultrasound. The subsequent trocars were positioned as needed (Fig. 1). Pneumoperitoneum pressure was limited to $10-12 \mathrm{mmHg}$ and kept as low as possible. Laparoscopic appendectomy and cholecystectomy were performed using a three-trocar technique with a $30^{\circ}$-angled optic. Both laparoscopic appendectomy and cholecystectomy were performed in a supine position and in the left lateral decubitus to prevent uterine compression of the inferior vena cava. Pneumatic sequential stockings were placed on the patient in the operating room and their use continued while the patient remains hospitalized. All patients received prophylactic low-dose heparin preoperatively. Administra-
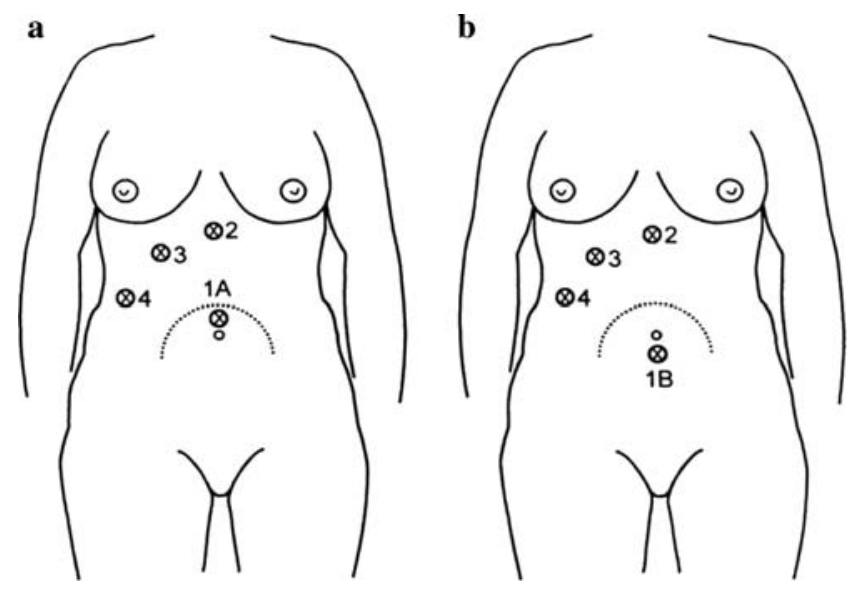

Fig. 1 Position of the trocars for a cholecystectomy and $\mathbf{b}$ appendectomy

tion of tocolytic agents (hexoprenaline-beta-2 sympathomimetic) and perioperative monitoring of fetal heart were routinely performed. No intraoperative cholangiography was performed.

\section{Results}

Out of more than 3,356 laparoscopic interventions (600 appendectomies and 1,800 cholecystectomies) in our institution, we found 16 patients who were operated during pregnancy. Eleven women underwent laparoscopic appendectomy and five underwent laparoscopic cholecystectomy. The operation was performed in the second and third trimester of pregnancy between weeks 22 and 32. Three patients were in the second trimester and 13 in the third trimester.

For the appendectomy, the diagnosis was a suspicion of acute appendicitis in all the cases. The diagnosis was made clinically. Ultrasonography was not done routinely and was positive for acute appendicitis in only one out of four cases. At the time of surgery, average gestational age was 26 weeks for appendicitis. Average operation time was $45 \mathrm{~min}(35-60 \mathrm{~min})$. In seven out of the eight cases the pathologist confirmed an acute appendicitis without perforation. In one case, the appendix was normal. For the cholecystectomy, indication for laparoscopy was acute cholecystitis with the presence of stones confirmed by ultrasonography in all the cases. Pathological examination of the gallbladder documented acute cholecystitis in all cases. At the time of surgery, median gestational age was 28 weeks. Operation time was $75 \mathrm{~min}$ (55-90 $\mathrm{min}$ ).

For all the patients, no intraoperative or postoperative complications occurred. Recovery was rapid and uneventful. The average hospital stay was 2.5 days for appendectomy and 4.5 days for cholecystectomy. No preterm labor occurred and all patients delivered normal healthy babies. 


\section{Discussion}

Nonobstetrical surgery during pregnancy was shown to be safe in a study over 5,405 operations on pregnant women without increases of congenital malformations or stillbirths, but with higher incidences of very-low, low-birth-weight infants, and death of infant during the first 168 days $[17,18]$. The laparoscopic procedure was safely performed in pregnant females in several published studies $[2,13,19$, 20], although the gravid condition has long been seen as a contraindication for laparoscopic surgical procedures [21]. Concerns included teratogenicity in the first trimester and preterm delivery during the second and third trimester. Direct uterine trauma, decreased uterine blood flow due to the pneumoperitoneum, and toxic narcotics drugs are possible causes [22-24]. The second trimester is considered the safest period to perform any surgery [25] because the uterus, due to its small volume, is less susceptible to traumatic injuries. But recently, some studies [26-34] have demonstrated that selected laparoscopic procedures can be performed safely during pregnancy even in the third trimester. Complications such as fetal loss and premature labor do occur, but can be kept around 5\% in the second trimester with the use of appropriate techniques. Guidelines were developed to ensure no increases in morbidity for the pregnant patient and to ensure that the safety of the fetus was not jeopardized [23, 35, 36].

There is a general consensus that laparoscopic procedures are safest when performed during the second trimester of pregnancy [21, 26, 37]. Hunter et al. [39] investigated the physiological impact of a $\mathrm{CO}_{2}$ pneumoperitoneum in these clinical settings. They concluded that a $\mathrm{CO}_{2}$ pneumoperitoneum created minimal impact on the patient and the fetus when using intraabdominal pressure of $15 \mathrm{mmHg}$ or less [38, 39, 40].

It was reported that intrauterine placement of a Veress needle can result in damage to the gravid uterus when creating a pneumoperitoneum in the pregnant patient $[2,14]$. The use of Hasson's trocar for open laparoscopy is usually considered safer especially with increased gestation age. It is essential to monitor the gravid patient and the fetus during the laparoscopic intervention. The gravid patient should be monitored carefully for oxygenation and hemodynamic status. Arterial blood gases and maternal end tidal $\mathrm{CO}_{2}$ should be obtained frequently Administration of tocolytic agents and perioperative monitoring of fetal heart tones should be routinely performed [23].

There are now numerous reports of laparoscopic appendectomies and cholecystectomies being performed in pregnant patients [41]. Almost all of these procedures were performed during the first and second trimester. Reported outcome studies showed that maternal morbidity is anecdotical and the fetal losses are rare. Potential advantages of laparoscopic appendectomy and cholecystectomy in the pregnant patient include decreased fetal depression due to lessened postoperative narcotic requirements, lower risks of wound complications, and diminished postoperative maternal hypoventilation [2].

Although surgical management of acute cholecystitis or choledocholithiasis is more accepted, surgical management of symptomatic cholecystolithiasis remains controversial. Recently a multicenter study compared medical vs surgical management of symptomatic cholelithiasis. In that study, surgery decreased the number of days in hospital and even reduced the rate of labor induction and preterm deliveries [42]. The nonsurgical management led to suboptimal clinical outcome in up to $38 \%$ of the women [42, 43]. That study clearly argues in favor of changing the management of gallstone disease during pregnancy from conservative or open cholecystectomy toward early laparoscopic cholecystectomy. We did not modify our management of choledocholithiasis in the gravid patient. As with other authors, our experience is limited in this particular setting and none of the patients in that study needed a common bile duct exploration for choledocholithiasis. We believe that using the appropriate protective measures, these patients are best managed by laparoscopic cholecystectomy with cystic duct cannulation and postoperative endoscopic retrograde cholangiopancreatography [25].

We suggest the following guidelines to improve the safety of laparoscopic procedures:

1. Obstetrical consultation should be obtained preoperatively.

2. When possible, operative intervention should be deferred until the second trimester when fetal risk is lowest.

3. The laparoscopic procedure should be performed in supine position and in the left lateral decubitus to prevent uterine compression of the inferior vena cava. The degree of reverse Trendelenburg's position should be as low as possible for visualization of the gallbladder and appendix.

4. To prevent puncture of the gravid uterus it is safer to use the open Hasson trocar technique.

5. Pneumoperitoneum pressures should be minimized to 8-12 $\mathrm{mmHg}$ and not allowed to exceed $15 \mathrm{mmHg}$.

6. Administration of tocolytic agents and perioperative monitoring of fetal heart tones should be routinely performed.

7. If an intraoperative cholangiography is necessary, the uterus should be protected with a lead shield. Fluoroscopy should be utilized selectively.

8. Because pneumoperitoneum enhances lower extremity venous stasis already present in the gravid patient and pregnancy induces a hypercoagulable state, pneumatic compression devices must be utilized. 


\section{Conclusion}

Laparoscopic surgery during pregnancy is not common and many surgeons are still reluctant to perform laparoscopic procedures. Nevertheless, we conclude that in a patient with strict indication, pregnancy is not a contraindication and laparoscopy can safely be performed in any trimester. Our results support laparoscopic management of appendicitis and symptomatic cholelithiasis during pregnancy, preferably in the second trimester. However, further study is required to better understand the effects of prolonged carbon dioxide pneumoperitoneum on fetal physiology.

Acknowledgment We would like to thank Dr. Paul Kretchmer (kretchmer@sfedit.net) at San Francisco Edit for his assistance in editing this manuscript.

\section{References}

1. Reedy MB, Galan HL, Richards WE, Preece CK, Wetter PA, Kuehl TJ (1997) Laparoscopy during pregnancy. A survey of laparoendoscopic surgeons. J Reprod Med 42(1):33-38

2. Spirtos NM, Eisenkop SM, Spirtos TW, Poliakin RI, Hibbard LT (1987) Laparoscopy - a diagnostic aid in cases of suspected appendicitis. Its use in women of reproductive age. Am J Obstet Gynecol 156(1):90-94

3. Kammerer WS (1979) Nonobstetric surgery during pregnancy. Drug Discov Today 63(6):1157-1164

4. Kammerer WS (1987) Nonobstetric surgery in pregnancy. Drug Discov Today 71(3):551-560

5. Hill LM, Johnson CE, Lee RA (1975) Cholecystectomy in pregnancy. Obstet Gynecol 46(3):291-293

6. Fallon WF Jr, Newman JS, Fallon GL, Malangoni MA (1995) The surgical management of intra-abdominal inflammatory conditions during pregnancy. Surg Clin North Am 75(1):15-31

7. Dufour P, Delebecq T, Vinatier D, Haentjens-Verbeke K, Tordjeman N, Prolongeau JF, Monnier JC, Puech F (1996) Appendicitis and pregnancy. Seven case reports. J Gynecol Obstet Biol Reprod (Paris) 25(4):411-415

8. Gurbuz AT, Peetz ME (1997) The acute abdomen in the pregnant patient. Is there a role for laparoscopy? Surg Endosc 11(2):98-102

9. Pucci RO, Seed RW (1991) Case report of laparoscopic cholecystectomy in the third trimester of pregnancy. Am J Obstet Gynecol 165(2):401-402

10. Schreiber JH (1990) Laparoscopic appendectomy in pregnancy. Surg Endosc 4(2):100-102

11. Ko CW, Beresford SA, Schulte SJ, Matsumoto AM, Lee SP (2005) Incidence, natural history, and risk factors for biliary sludge and stones during pregnancy. Hepatology 41(2):359-365

12. Slim K, Canis M (1998) Laparoscopic surgery and pregnancy. J Chir (Paris) 135(6):261-266

13. Curet MJ, Allen D, Josloff RK, Pitcher DE, Curet LB, Miscall BG, Zucker KA (1996) Laparoscopy during pregnancy. Arch Surg 131(5):546-550

14. Morrell DG, Mullins JR, Harrison PB (1992) Laparoscopic cholecystectomy during pregnancy in symptomatic patients. Surgery 112(5):856-859

15. Rollins MD, Chan KJ, Price RR (2004) Laparoscopy for appendicitis and cholelithiasis during pregnancy: a new standard of care. Surg Endosc 18(2):237-241
16. Holthausen UH, Mettler L, Troidl H (1999) Pregnancy: a contraindication? World J Surg 23(8):856-862

17. Mazze RI, Kallen B (1989) Reproductive outcome after anesthesia and operation during pregnancy: a registry study of 5405 cases. Am J Obstet Gynecol 161(5):1178-1185

18. Kort B, Katz VL, Watson WJ (1993) The effect of nonobstetric operation during pregnancy. Surg Gynecol Obstet 177(4): 371-376

19. Affleck DG, Handrahan DL, Egger MJ, Price RR (1999) The laparoscopic management of appendicitis and cholelithiasis during pregnancy. Am J Surg 178(6):523-529

20. Curet MJ (2000) Special problems in laparoscopic surgery. Previous abdominal surgery, obesity, and pregnancy. Surg Clin North Am 80(4):1093-1110

21. Steinbrook RA, Brooks DC, Datta S (1997) Laparoscopic surgery during pregnancy. Am J Surg 174(2):222

22. Friedman RL, Friedman IH (1995) Acute cholecystitis with calculous biliary duct obstruction in the gravid patient. Management by ERCP, papillotomy, stone extraction, and laparoscopic cholecystectomy. Surg Endosc 9(8): 910-913

23. Costantino GN, Vincent GJ, Mukalian GG, Kliefoth WL Jr (1994) Laparoscopic cholecystectomy in pregnancy. J Laparoendosc Surg 4(2):161-164

24. Fatum M, Rojansky N (2001) Laparoscopic surgery during pregnancy. Obstet Gynecol Surv 56(1):50-59

25. Williams JK, Rosemurgy AS, Albrink MH, Parsons MT, Stock S (1995) Laparoscopic cholecystectomy in pregnancy. A case report. J Reprod Med 40(3):243-245

26. Amos JD, Schorr SJ, Norman PF, Poole GV, Thomae KR, Mancino AT, Hall TJ, Scott-Conner CE (1996) Laparoscopic surgery during pregnancy. Am J Surg 171(4):435-437

27. Arvidsson D, Gerdin E (1991) Laparoscopic cholecystectomy during pregnancy. Surg Laparosc Endosc 1(3):193-194

28. Beebe DS, McNevin MP, Crain JM, Letourneau JG, Belani KG, Abrams JA, Goodale RL (1993) Evidence of venous stasis after abdominal insufflation for laparoscopic cholecystectomy. Surg Gynecol Obstet 176(5):443-447

29. Martin IG, Dexter SP, McMahon MJ (1996) Laparoscopic cholecystectomy in pregnancy. A safe option during the second trimester? Surg Endosc 10(5):508-510

30. Posta CG (1995) Laparoscopic surgery in pregnancy: report on two cases. J Laparoendosc Surg 5(3):203-205

31. Soper NJ, Hunter JG, Petrie RH (1992) Laparoscopic cholecystectomy during pregnancy. Surg Endosc 6(3):115-117

32. Windberger U, Siegl H, Ferguson JG, Schima H, Fugger R, Herbst F, Schemper M, Losert U (1995) Hemodynamic effects of prolonged abdominal insufflation for laparoscopic procedures. Gastrointest Endosc 41(2):121-129

33. Barnes SL, Shane MD, Schoemann MB, Bernard AC, Boulanger BR (2004) Laparoscopic appendectomy after 30 weeks pregnancy: report of two cases and description of technique. Am Surg 70 (8):733-736

34. de Perrot M, Jenny A, Morales M, Kohlik M, Morel P (2000) Laparoscopic appendectomy during pregnancy. Surg Laparosc Endosc Percutan Tech 10(6):368-371

35. Iafrati MD, Yarnell R, Schwaitzberg SD (1995) Gasless laparoscopic cholecystectomy in pregnancy. J Laparoendosc Surg 5 (2): $127-130$

36. Society of American Gastrointestinal Endoscopic Surgeons (SAGES) (1998) Guidelines for laparoscopic surgery during pregnancy. Surg Endosc 12(2):189-190

37. Conron RW Jr, Abbruzzi K, Cochrane SO, Sarno AJ, Cochrane PJ (1999) Laparoscopic procedures in pregnancy. Am Surg 65 (3):259-263 
38. Curet MJ, Vogt DA, Schob O, Qualls C, Izquierdo LA, Zucker KA (1996) Effects of CO2 pneumoperitoneum in pregnant ewes. J Surg Res 63(1):339-344

39. Hunter JG, Swanstrom L, Thornburg K (1995) Carbon dioxide pneumoperitoneum induces fetal acidosis in a pregnant Ewe model. Surg Endosc 9(3):272-277

40. Paolucci V, Schaeff B, Gutt CN, Encke A (1995) The gasless laparoscopic cholecystectomy. Endosc Surg Allied Technol 3 (1):76-80
41. Mazze RI, Kallen B (1991) Appendectomy during pregnancy: a Swedish registry study of 778 cases. Obstet Gynecol 77(6): 835-840

42. Lu EJ, Curet MJ, El Sayed YY, Kirkwood KS (2004) Medical versus surgical management of biliary tract disease in pregnancy. Am J Surg 188(6):755-759

43. Visser BC, Glasgow RE, Mulvihill KK, Mulvihill SJ (2001) Safety and timing of nonobstetric abdominal surgery in pregnancy. Dig Surg 18(5):409-417 